\title{
Antigenotoxic Potential of Rutin and Quercetin in Swiss Mice Exposed to Gamma Radiation
}

\author{
Shrikant L. Patil ${ }^{1}$, Nageshwar B. Rao ${ }^{2}$, H. M. Somashekarappa ${ }^{3}$, K. P. Rajashekhar ${ }^{4}$
}

Background: Ionizing radiation induces a variety of genetic damages through the formation free radicals such as reactive oxygen species (ROS). Appropriate antioxidant intervention may inhibit or reduce free radical toxicity and thus offer protection against radiation. Rutin (RUT) and quercetin (QRT) are flavonoids known to be potent dietary antioxidants.

Methods: The present study tested the antigenotoxic effect of RUT and QRT in vivo against radiation- induced chromosomal damage. Swiss albino mice were administered orally with RUT and QRT (10 and $20 \mathrm{mg} / \mathrm{kg}$ b.wt.) once daily for five consecutive days. One hour after the last administration of RUT and QRT on the fifth day, the animals were whole body exposed to $3 \mathrm{~Gy}$ gamma radiation. The anti-genotoxic potential was assessed in terms of chromosomal aberrations, micronucleus test, and alkaline comet assay.

Results: $\quad$ Significant decline in dicentric formation was observed in RUT and QRT treated group. Further, the antigenotoxic potential of RUT and QRT caused a significant $(p<0.001)$ reduction in micronucleated polychromatic, normochromatic erythrocytes; increased PCE/NCE ratio was observed in the RUT and QRT treated group. Administration of RUT and QRT before irradiation resulted in a significant $(p<0.01)$ decrease in the DNA damage at the post-irradiation time when compared with irradiation alone group.

\begin{abstract}
At a Glance Commentary
Scientific background of the subject

Ionizing radiation generates free radicals that damage DNA and kill cells. Ionizing radiation, employed in radiotherapy for various cancers, is not exclusive in its action because it affects both tumor cells and normal cells. In this regard, numerous chemicals possess dependable defenses against radiation-induced damage in experimental animals and cultured cells, but their clinical efficacy is limited by drug toxicity with repeated administration. Search for the effective and nontoxic radioprotective agents that are able to protect human beings from the ionizing radiation is of considerable interest for radiation medicine, space flights, and nuclear emergencies.
\end{abstract}

\section{What this study adds to the field}

Rutin (RUT) and quercetin (QRT) have potent antigenotoxic potential, which warrants further investigations into the mechanistic action of RUT and QRT as possible radioprotectors.

Conclusions: Present findings demonstrate the potential of RUT and

QRT in mitigating radiation-induced mortality and cytogenetic damage, which may be attributed to scavenging of radiation-induced free radicals.

(Biomed J 2014;37:305-313)

Key words: chromosomal aberrations, comet assay, micronucleus test, quercetin, rutin

$\mathrm{R}$ adiation therapy is the prime treatment modality against various cancers. However, its use is limited due to the lethal effects of radiation on normal tissues. ${ }^{[1]}$ Therefore, attempts were made earlier to improve the therapeutic effect of radiotherapy by keeping the normal tissue damage to acceptable level by using synthetic compounds like cysteine, cysteamine, and WR-2721. ${ }^{[2]}$ However, the successful use of these radioprotectants in medical practice is not appreciated much due to their inherent systemic toxicity and biological short half-life.

From the ${ }^{1}$ Department of Physiology, K. S. Hegde Medical Academy, Nitte University, Mangalore, Karnataka, India; ${ }^{2}$ Division of Radiobiology and Toxicology, Manipal Life Sciences Centre, Manipal University, Manipal, Karnataka, India; ${ }^{3}$ Centre for Application of Radioisotopes and Radiation Technology, USIC, Mangalore, Karnataka, India; ${ }^{4}$ Department of Applied Zoology, Mangalore University, Mangalore, India Received: Mar. 03, 2013; Accepted: Oct. 02, 2013

Correspondence to: Dr. Shrikant L. Patil, Department of Physiology, K. S. Hegde Medical Academy, Nitte University, Mangalore, Karnataka, India. Deralakatte, Mangalore, Karnataka - 575 018, India. Tel: 0824-2204490 ext. 210; Fax: 0824-2204162;

E-mail: shrikantlpatil@gmail.com

DOI: $10.4103 / 2319-4170.132880$ 
Therefore, the quest for effective, nontoxic compound with its optimal radioprotective capability is of immediate need, which shifted the interest more on the naturally occurring dietary antioxidants. A number of dietary antioxidants, medicinal plant extracts, and their isolated constituents have been reported for their hepatoprotective, neuroprotective, anti-inflammatory and also antioxidant or radical-scavenging properties. ${ }^{[2-4]}$ Several earlier studies on some of the medicinal plants ${ }^{[5-8]}$ have indicated the usefulness of these natural products in reducing the radiation-induced genotoxicity and animal mortality.

Flavonoids are a family of polyphenolic compounds found in fruits and vegetables. They have wide-ranging biological properties including antibacterial, antiviral, anticancer, immunostimulant, and antioxidant effects. ${ }^{[9]}$ Ionizing radiation generates free radical damage in DNA and induces genotoxic effects and death in the cells. ${ }^{[10]}$ Free radical scavenging is apparently responsible for the protective effect of flavonoids such as rutin (RUT), morin, quercetin (QRT), and genestin on the clastogenic activity induced by gamma radiation in mice. ${ }^{[11]}$ In addition, QRT exerts potent antioxidant activity and vitamin $\mathrm{C}$ sparing action. ${ }^{[12,13]}$ The present study was undertaken to elucidate the radioprotective and antigenotoxic potential of RUT and QRT in whole-body irradiated mice.

\section{METHODS}

\section{Animals}

Four to six weeks old inbred mice of Swiss albino strain of either sex weighing 25-30 g were selected, and kept in well-ventilated polypropylene cages under standard conditions of temperature $\left(23 \pm 2^{\circ} \mathrm{C}\right)$, humidity $(50 \pm 5 \%)$, and light (10 and $14 \mathrm{~h}$ of light and dark, respectively). Animals were allowed food and water ad libitum. The animal experiments were carried out with the prior approval from the Institutional Animal Ethics Committee. Animal care and handling was done according to the guidelines issued by the World Health Organization, Geneva, Switzerland and the Indian National Science Academy, New Delhi, India.

\section{Chemicals}

\section{Drug preparation and mode of administration}

RUT and QRT were purchased from Himedia Laboratories Pvt Ltd (Mumbai, India). RUT and QRT powder was suspended in water using $0.5 \% \mathrm{w} / \mathrm{v}$ carboxy methyl cellulose (CMC) and was given once daily ( $5 \mathrm{ml} / \mathrm{kg} \mathrm{b.wt}$.). Various doses of RUT and QRT (10-100 mg/kg b wt.) were given orally once a day for five consecutive days. Radiation exposure was performed $1 \mathrm{~h}$ after the last dose of RUT and QRT administration.

\section{Other chemicals}

RUT and QRT, glutathione, chloro-2,4-dinitrobenzene (CDNB), 5,5-dithiobis-2-nitrobenzoic acid (DTNB), trichloroacetic acid (TCA), thiobarbituric acid (TBA), ethidium bromide, normal melting agarose (NMA), low melting agarose (LMA), and fetal bovine serum (FBS) were purchased from Sigma Chemical Co. (St. Louis, MO, USA). Acridine orange (AO) was purchased from BDH Chemicals Ltd (Poole, England). The other chemicals such as absolute alcohol, dimethyl sulfoxide (DMSO), ethylenediaminetetraacetic acid (EDTA), sodium bicarbonate, sodium chloride, potassium hydrogen phosphate, and hydrochloric acid were purchased from Qualigens Fine Chemicals (a division of GlaxoSmithKline Pharmaceuticals), Mumbai, India.

\section{Radiation exposure}

Unanesthetized mice were restrained in a specially designed well-ventilated acrylic box and exposed to whole-body radiation from ${ }^{60} \mathrm{Co}$ gamma tele-therapy facility (Theratron Atomic Energy Agency, Canada) at the Shirdi Sai Baba Cancer Hospital, Manipal, at a dose rate of $1.33 \mathrm{~Gy} / \mathrm{min}$ and source-to-surface distance (SSD) of $61 \mathrm{~cm}$.

\section{Chromosomal study}

After the exposure to gamma radiation, four animals from each group at $24 \mathrm{~h}$ were selected randomly for chromosomal study. Animals were given $0.2 \mathrm{ml} / 100 \mathrm{~g}$ b.wt. colchicines $(50 \mathrm{mg} \% \mathrm{w} / \mathrm{v})$ i.p., $3 \mathrm{~h}$ before they were sacrificed by cervical dislocation. Bone marrow from the femur bone was aspirated and the cells were centrifuged, treated with hypotonic salt solution $(0.56 \% \mathrm{KCl})$, fixed in methanolacetic acid (3:1), and metaphase plates were prepared by the air-drying method (modified G-banding technique). Slides were stained with 3\% Giemsa (Sigma-Aldrich, Mumbai, India.) and aberrations of 100 metaphases were scored from each mouse on the fluorescent microscope. Chromosomal analysis was carried out exclusively on first-division metaphases containing 46 centromeres. Chromosomal abnormalities were classified as follows: Dicentric chromosomes (dic) and rings (r) only scored when an acentric fragment was present; acentric fragments, not associated with dicentric and ring chromosomes, were classified as extra acentric fragments (ace). Translocations and inversions were only recorded when the morphology of the derivative chromosome was clearly indicative of this kind of rearrangement. Other abnormalities like chromatid breaks (chtb) and gaps were also recorded. It is a known fact that after gamma irradiation, the cell distribution of dicentrics follows a Poisson, and in order to have the same accuracy in all RUT treatments, the number of analyzed cells was those needed to score 100 dicentrics. 


\section{Micronucleus assay}

\section{Selection of optimal dose of RUT and QRT against gamma radiation}

The mouse bone marrow MN test was carried out according to the method described by Schmid. ${ }^{[14]}$ The radiation dose of $3 \mathrm{~Gy}$ was selected for MN assay to make sure of obtaining sufficient number of polychromatic erythrocytes (PCE)/normochromatic erythrocytes (NCE) post irradiation. Animals were divided into the following groups consisting of four animals each.

1. Untreated control group: The animals of this group were administered orally with $0.1 \mathrm{ml} / \mathrm{kg}$ b.wt. CMC suspended in water for five consecutive days.

2. RUT and QRT alone group: The animals of this group were administered with various doses of RUT and QRT (10, 20, 40, 60, and $80 \mathrm{mg} / \mathrm{kg}$ b.wt.) alone orally once daily for five consecutive days.

3. Radiation alone group: The animals of this group were administered orally with $0.1 \mathrm{ml} / \mathrm{kg}$ b.wt. of CMC orally for five consecutive days. One hour after the last administration on the fifth day, the animals were exposed to 3 Gy of gamma radiation.

4. RUT and QRT + radiation group: The animals of this group were given various doses $(10,20,40,60$, and $80 \mathrm{mg} / \mathrm{kg}$ b.wt.) of RUT and QRT orally once daily for five consecutive days. One hour after the last administration on the fifth day, the animals were exposed to $3 \mathrm{~Gy}$ of gamma radiation.

All the animals were euthanized $24 \mathrm{~h}$ after irradiation for optimal RUT and QRT dose selection experiment. The femurs from each animal were dissected out; bone marrow cells were flushed into phosphate-buffered saline (PBS) separately. Cells were centrifuged at $3000 \mathrm{rpm}$ for $10 \mathrm{~min}$; the cell pellet was mixed with few drops of FBS and smeared on a clean glass slide. The slides were air-dried and fixed in absolute methanol. Cells were stained with $0.01 \% \mathrm{AO}$ in Sorensen's buffer ( $\mathrm{pH}$ 6.8) and observed under a fluorescent microscope (Carl Zeiss Photomicroscope III, Oberkochen, Germany) using a 40 Neofluar objective.

In a total of 1000 PCE and the same number of NCE from each group, the frequency of micronucleated polychromatic erythrocytes (MnPCE) and micronucleated normochromatic erythrocytes (MnNCE) was determined. Polychromatic and normochromatic erythrocyte ratio (PCE/NCE) is an indicator of the acceleration or inhibition of erythropoiesis. Data regarding the $\mathrm{PCE} / \mathrm{NCE}$ ratio were also collected, where a total of 4000 erythrocytes per animal were scored.

\section{Single cell gel electrophoresis for DNA damage}

To evaluate the antigenotoxic potential of RUT and QRT against gamma radiation, animals were divided into the following groups with four animals per group.

1. Untreated control group: The animals of this group were administered with $0.1 \mathrm{ml} / \mathrm{kg}$ b.wt. of CMC orally for five consecutive days.

2. RUT and QRT alone group: The animals of this group were administered with optimum dose of RUT and QRT (10 and $20 \mathrm{mg} / \mathrm{kg}$ b.wt.) orally for five consecutive days.

3. Radiation alone group: These animals were administered with CMC orally once daily for five consecutive days. One hour after the last administration on the fifth day, the animals were exposed to $3 \mathrm{~Gy}$ gamma radiation.

4. RUT and QRT + radiation group: The animals of this group were administered with optimal dose of RUT and QRT (10 and $20 \mathrm{mg} / \mathrm{kg}$ b.wt.) orally for five consecutive days, and the last dose of RUT and QRT was given just $1 \mathrm{~h}$ before exposure to $3 \mathrm{~Gy}$ of gamma radiation.

SCGE provides a rapid, visual method for assessing DNA breakage quantitatively in single cell. DNA damage is visualized at the individual cell level as an increased migration of genetic material (comet tail) from the nucleus (comet head). Blood was collected from the orbital sinus of each animal from each group in a vial containing $0.5 \mathrm{M}$ EDTA at $24 \mathrm{~h}$ post irradiation and processed for comet assay.

\section{Statistical analysis}

All data were expressed as mean \pm standard error of mean (SEM). Statistical significance $(p<0.05)$ was considered as significant. Student's $t$-test was used for all the biochemical estimations. All statistical analyses were carried out using Statistical Package for Social Sciences (SPSS) version 10.0 for Windows.

\section{RESULTS}

\section{Chromosome aberrations in mouse bone marrow after $24 \mathrm{~h}$ of exposure to $3 \mathrm{~Gy}$ whole-body gamma radiation}

There was a significant negative correlation between the RUT and QRT (10 and $20 \mathrm{mg} / \mathrm{kg}$ b.wt.) treatment and the frequency of dicentrics. The decrease with respect to the untreated group was significant. Similar results were obtained when dicentrics plus rings were considered. The distribution of cells containing different number of dicentrics and the frequencies is shown in Table 1, and in all cases, it follows a Poisson distribution. The inter-cellular distribution of dicentrics and dicentrics plus rings follows a Poisson distribution in all cases with or without RUT and QRT. Departures from Poisson were assessed in terms of the test quantity U. Correlation was assessed using Spearman's rank correlation coefficient. 


\section{MN assay}

\section{Selection of optimum dose}

The effect of gamma radiation with or without RUT and QRT on the induction of MnPCE, MnNCE, and $\mathrm{PCE} / \mathrm{NCE}$ ratio in bone marrow cells after $24 \mathrm{~h}$ is shown in Figures 1 and 2. The animals treated with $80 \mathrm{mg} / \mathrm{kg}$ b.wt. (highest dose of RUT and QRT) did not induce MPCE and MNCE, indicating the nontoxic nature of RUT and QRT. Treatment of mice with different doses of RUT and QRT before exposure to 3 Gy of gamma radiation caused a significant $(p<0.01)$ decline in the radiation-induced MPCE and MNCE formation when compared with the non-drug-treated irradiated animals. A lowest value of MnPCE and MnNCE frequency was observed at the optimal dose of $10 \mathrm{mg} / \mathrm{kg}$ b.wt. of RUT and $20 \mathrm{mg} / \mathrm{kg}$ b.wt. of QRT. However, treatment with RUT (10 mg/kg b.wt.) and QRT (20 mg/kg b.wt.) prior to irradiation significantly increased the ratio when compared with the respective irradiated groups. Also, $10 \mathrm{mg} / \mathrm{kg}$ b.wt. of RUT and $20 \mathrm{mg} / \mathrm{kg}$ b.wt. of QRT were selected as the optimal doses for further studies [Figures 1 and 2].

\section{Radioprotective effect}

Irradiation of mice with different doses of gamma radiation resulted in a significant dose-dependent elevation

Table 1: Frequency of chromosomal aberrations (mean \pm SEM) in mouse bone marrow after 24 h of exposure to 3 Gy whole-body gamma radiation in various treatment groups of mice $(n=4)$

\begin{tabular}{|c|c|c|c|c|c|c|c|c|}
\hline \multirow[t]{2}{*}{ Treatment group } & \multirow{2}{*}{$\begin{array}{c}\text { Chromosome } \\
\text { breaks }\end{array}$} & \multirow{2}{*}{$\begin{array}{c}\text { Chromatid } \\
\text { breaks }\end{array}$} & \multicolumn{3}{|c|}{ Types of aberrations } & \multirow[t]{2}{*}{ Exchanges } & \multirow{2}{*}{$\begin{array}{c}\text { Total } \\
\text { aberrations }\end{array}$} & \multirow[t]{2}{*}{$\%$ Aberrations } \\
\hline & & & Acentric fragments & Dicentrics & Rings & & & \\
\hline Untreated & $0.09 \pm 0.02$ & $0.15 \pm 0.15$ & $0.18 \pm 0.10$ & - & $0.08 \pm 0.05$ & - & $1.05 \pm 0.20$ & 1.05 \\
\hline Irradiated & $0.13 \pm 0.02$ & $0.25 \pm 0.05$ & $0.92 \pm 0.10$ & $0.32 \pm 0.55$ & $0.15 \pm 0.02$ & $0.33 \pm 0.05$ & $2.12 \pm 0.35^{*}$ & 2.12 \\
\hline RUT (10 mg/kg b.wt.) & $0.10 \pm 0.03$ & $0.13 \pm 0.06$ & $0.29 \pm 0.08$ & $0.22 \pm 0.03$ & $0.06 \pm 0.02$ & $0.40 \pm 0.01$ & $1.19 \pm 0.20 *$ & 1.1 \\
\hline QRT (20 mg/kg b.wt.) & $0.11 \pm 0.01$ & $0.14 \pm 0.03$ & $0.30 \pm 0.08$ & $0.23 \pm 0.01$ & $0.05 \pm 0.01$ & $0.30 \pm 0.02$ & $1.12 \pm 0.20 *$ & 1.2 \\
\hline RUT+IR & $0.16 \pm 0.05$ & $0.17 \pm 0.08$ & $0.52 \pm 0.05$ & $0.19 \pm 0.05$ & $0.19 \pm 0.03$ & $0.26 \pm 0.08$ & $1.48 \pm 0.22 *$ & 1.48 \\
\hline QRT+IR & $0.19 \pm 0.03$ & $0.21 \pm 0.06$ & $0.55 \pm 0.12$ & $0.20 \pm 0.02$ & $0.20 \pm 0.05$ & $0.28 \pm 0.06$ & $1.62 \pm 0.18^{*}$ & 1.62 \\
\hline
\end{tabular}

* $p<0.01$. Abbreviations: SEM: Standard error of mean; RUT: Rutin; QRT: Quercetin; IR: Irradiated
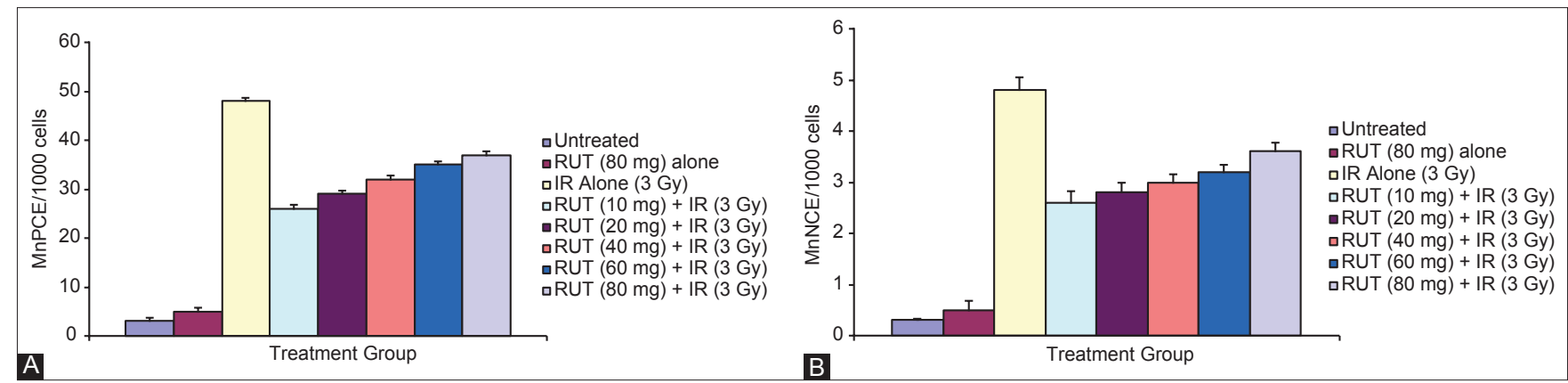

Figure 1: Effect of different doses of rutin on the bone marrow of mice exposed to 3 Gy of gamma radiation: (A) the micronucleated polychromatic erythrocytes; (B) the micronucleated normochromatic erythrocytes. Statistically significant level was $p<0.05$; RUT treated groups compared with 3 Gy IR alone group.
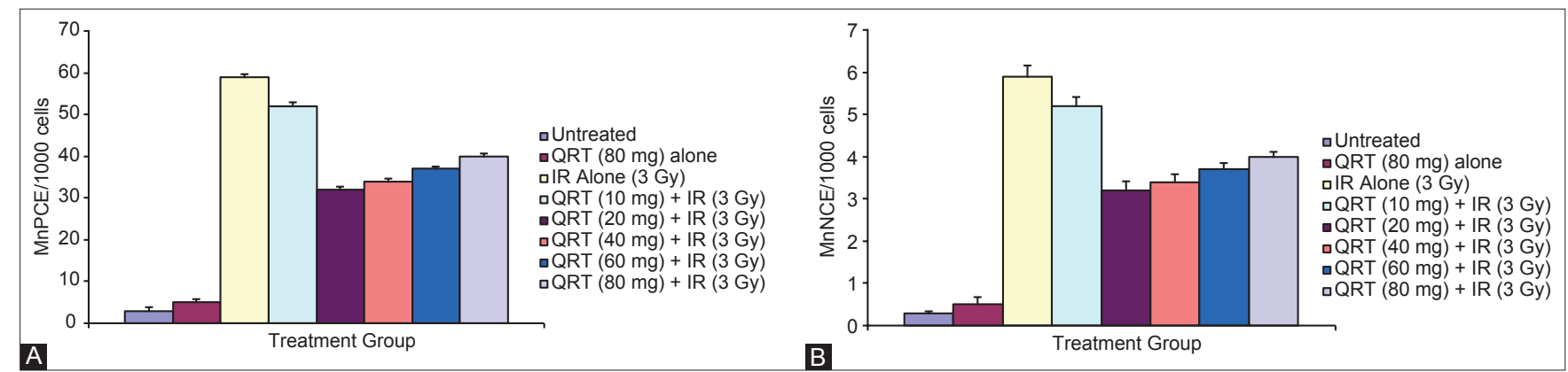

Figure 2: Effect of different doses of quercetin on the bone marrow of mice exposed to 3 Gy of gamma radiation: (A) the micronucleated polychromatic erythrocytes; (B) the micronucleated normochromatic erythrocytes. Statistically significant level was $p<0.05$, QRT treated groups compared with 3 Gy IR alone group. 
in the frequency of MnPCE and MnNCE and a decline in the $\mathrm{PCE} / \mathrm{NCE}$ ratio at various post-irradiation time periods [Tables 2 and 3]. The frequency of MnPCE and MnNCE increased significantly at $24 \mathrm{~h}$ post irradiation. Pretreatment with RUT and QRT significantly reduced the frequency of MPCE and MNCE when compared with irradiation alone groups at all post-irradiation time periods. Exposure of mice to different doses of gamma radiation resulted in a dose-dependent decline in the PCE/NCE ratio when compared with sham irradiation. The PCE/NCE ratio in the RUT + irradiation and QRT + irradiation group was significantly $(p<0.01)$ higher when compared with the respective radiation alone group at all post-irradiation time periods.

\section{Comet assay}

Damage to cellular DNA in vivo induced by whole-body gamma radiation exposure (3 Gy) to mice was studied by alkaline comet assay. The exposure of animals to radiation increased comet parameters like percent of DNA in tail and olive tail movement (OTM) of blood leukocytes, suggesting radiation-induced damage to DNA. As seen in Tables 4 and 5, when the animals were exposed to gamma irradiation, there was indication of the DNA damage as analyzed by percent DNA in tail and mean OTM. The OTM in blood cells was increased to $15.23 \pm 0.77$ and $8.96 \pm 0.75$ in RUT and QRT treated groups, respectively, when compared with the control group. Whereas administration of RUT and
QRT before irradiation resulted in a significant $(p<0.01)$ decrease in the OTM at all the post-irradiation time periods when compared with IR alone group.

\section{DISCUSSION}

The present study was aimed to understand the role of the natural antioxidants RUT and QRT in streamlining radiation-induced DNA damage against hemopoietic cells of Swiss mice. Ionizing radiation has been reported as an indispensable tool for treatment of cancer due to its genotoxic nature to the proliferating cells, thereby resulting in tumor cell death. Although the radiation treatment has been reported to have great impact on cancer therapy, it is associated with some carcinogenic side effects through the direct or indirect effects on a variety of DNA lesions ${ }^{[15]}$ as well as therapy-associated normal tissue toxicities. ${ }^{[16]}$ In response to radiation, DNA repair plays critical roles in protecting cells from genomic instability. ${ }^{[17,18]}$

Therefore, the success of radiation therapy depends on its ability not only to kill cancer cells but also in avoiding damage to normal cells. There are reports available stating that antioxidants protect cells against DNA damage induced by reactive oxygen species (ROS) ${ }^{[19]}$ and can also have the potential to reduce oncogenesis. ${ }^{[20]}$ Antioxidants from dietary sources would be easily tolerable with their organically attainable concentrations and may be more safely controlled in patients undergoing radiotherapy. RUT and QRT are

Table 2: The effect of RUT on the radiation-induced micronuclei and PCE/NCE ratio in the bone marrow of mice ( $n=4)$

\begin{tabular}{|c|c|c|c|c|c|c|}
\hline \multirow[t]{2}{*}{ Dose (Gy) } & \multicolumn{2}{|c|}{ MPCE/1000 } & \multicolumn{2}{|c|}{ MNCE/1000 } & \multicolumn{2}{|c|}{ PCE/NCE } \\
\hline & IR alone & RUT+IR & IR alone & RUT+IR & IR alone & RUT+IR \\
\hline 0 & $2.48 \pm 0.36$ & $2.97 \pm 0.12$ & $0.69 \pm 0.19$ & $0.60 \pm 0.17$ & $1.12 \pm 0.04$ & $1.22 \pm 0.07$ \\
\hline 1 & $24.17 \pm 0.97$ & $10.91 \pm 1.14^{\mathrm{c}}$ & $2.44 \pm 0.28$ & $1.69 \pm 0.78^{\mathrm{a}}$ & $0.92 \pm 0.06$ & $0.98 \pm 0.07^{\mathrm{b}}$ \\
\hline 2 & $34.11 \pm 3.07$ & $19.84 \pm 1.63^{c}$ & $4.05 \pm 0.33$ & $1.93 \pm 0.22^{\mathrm{a}}$ & $0.92 \pm 0.08$ & $0.97 \pm 0.02^{b}$ \\
\hline 3 & $43.19 \pm 1.86$ & $30.21 \pm 3.02^{\mathrm{c}}$ & $3.97 \pm 0.19$ & $2.25 \pm 0.40^{\mathrm{c}}$ & $0.84 \pm 0.05$ & $0.91 \pm 0.03$ \\
\hline 4 & $86.52 \pm 2.95$ & $71.32 \pm 2.13^{b}$ & $7.65 \pm 0.09$ & $2.65 \pm 0.21^{\mathrm{c}}$ & $0.47 \pm 0.05$ & $0.71 \pm 0.03^{\mathrm{b}}$ \\
\hline
\end{tabular}

Animals were administered RUT (10 mg/kg b.wt.) for five consecutive days. On the fifth day, mice were exposed to different doses of gamma radiation (1-4 Gy). The percentage of micronucleated polychromatic erythrocytes, micronucleated normochromatic erythrocytes, and PCE/NCE ratio were derived. Values are mean \pm SEM for four mice per group. Abbreviations: IR: Radiation alone; RUT+IR: Rutin+radiation. Rutin+irradiation group compared with the respective IR group: $\mathrm{a}=p<0.05 ; \mathrm{b}=p<0.01 ; \mathrm{c}=p<0.001$; No symbol: Non-significant

Table 3: The effect of QRT on the radiation-induced micronuclei and PCE/NCE ratio in the bone marrow of mice $(n=4)$

\begin{tabular}{|c|c|c|c|c|c|c|}
\hline \multirow[t]{2}{*}{ Dose (Gy) } & \multicolumn{2}{|c|}{ MPCE/1000 } & \multicolumn{2}{|c|}{ MNCE/1000 } & \multicolumn{2}{|c|}{ PCE/NCE } \\
\hline & IR alone & QRT+IR & IR alone & QRT+IR & IR alone & QRT+IR \\
\hline 0 & $2.48 \pm 0.36$ & $2.74 \pm 0.19$ & $0.69 \pm 0.19$ & $0.63 \pm 0.22$ & $1.12 \pm 0.04$ & $1.26 \pm 0.05$ \\
\hline 1 & $24.17 \pm 0.97$ & $16.24 \pm 1.12^{\mathrm{b}}$ & $2.44 \pm 0.28$ & $1.83 \pm 0.116^{\mathrm{a}}$ & $0.92 \pm 0.06$ & $1.25 \pm 0.09^{\mathrm{a}}$ \\
\hline 2 & $34.11 \pm 3.07$ & $25.25 \pm 0.98^{b}$ & $4.05 \pm 0.33$ & $2.25 \pm 0.16^{\mathrm{b}}$ & $0.92 \pm 0.08$ & $0.98 \pm 0.06^{\mathrm{b}}$ \\
\hline 3 & $43.19 \pm 1.86$ & $37.79 \pm 3.04^{b}$ & $3.97 \pm 0.19$ & $2.93 \pm 0.21^{\mathrm{b}}$ & $0.84 \pm 0.05$ & $0.89 \pm 0.03$ \\
\hline 4 & $86.52 \pm 2.95$ & $76.195 \pm 2.98^{b}$ & $7.65 \pm 0.09$ & $4.77 \pm 0.33^{\mathrm{b}}$ & $0.47 \pm 0.05$ & $0.76 \pm 0.03^{b}$ \\
\hline
\end{tabular}

Animals were administered QRT (20 mg/kg b.wt.) for five consecutive days. On the fifth day, mice were exposed to different doses of gamma radiation (1-4 Gy). The percentage of micronucleated polychromatic erythrocytes, micronucleated normochromatic erythrocytes, and PCE/NCE ratio were derived. Values are mean \pm SEM for four mice per group. Abbreviations: IR: Radiation alone; QRT+IR: Quercetin+radiation. QRT+irradiation group compared with the respective IR group: $\mathrm{a}=p<0.05 ; \mathrm{b}=p<0.01 ; \mathrm{c}=p<0.001$; No symbol: Non-significant 
Table 4: Effect of optimal concentration of RUT $(10 \mathrm{mg} / \mathrm{kg}$ b.wt.) on the radiation-induced DNA damage in the peripheral blood leukocytes of mice assessed by comet assay $(n=4)$

\begin{tabular}{lcc}
\hline Groups & \multicolumn{2}{c}{ Comet parameters } \\
\cline { 2 - 3 } & \% Tail DNA & OTM \\
\hline Untreated & $6.94 \pm 0.78$ & $2.95 \pm 0.22$ \\
RUT $(10 \mathrm{mg})$ alone & $7.79 \pm 0.89$ & $3.29 \pm 0.39$ \\
IR alone (3 Gy) & $27.22 \pm 1.47$ & $24.12 \pm 1.49$ \\
RUT+IR & $17.44 \pm 1.05^{\mathrm{a}}$ & $15.23 \pm 0.77^{\mathrm{a}}$
\end{tabular}

Animals were administered RUT (10 mg/kg b.wt.) for five consecutive days. On the fifth day, mice were exposed to $3 \mathrm{~Gy}$ of gamma radiation.

The blood was collected $24 \mathrm{~h}$ post-irradiation time and assessed for comet assay. Values are mean \pm SEM for four mice per group. Abbreviations: IR: Radiation alone; RUT+IR: Rutin+radiation; OTM: Olive tail moment; RUT+irradiation group compared with respective IR group: $\mathrm{a}=p<0.05$

Table 5: Effect of optimal concentration of QRT $(20 \mathrm{mg} / \mathrm{kg}$ b.wt.) on the radiation-induced DNA damage in the peripheral blood leukocytes of mice assessed by comet assay $(n=4)$

\begin{tabular}{lcc}
\hline Groups & \multicolumn{2}{c}{ Comet parameters } \\
\cline { 2 - 3 } & \% Tail DNA & OTM \\
\hline Untreated & $5.98 \pm 0.44$ & $2.95 \pm 0.31$ \\
QRT $(20 \mathrm{mg})$ alone & $7.06 \pm 0.90$ & $3.12 \pm 0.27$ \\
IR alone (3 Gy) & $22.33 \pm 2.01$ & $17.40 \pm 1.37$ \\
QRT+IR & $14.88 \pm 1.57^{\mathrm{b}}$ & $8.96 \pm 0.75^{\mathrm{b}}$ \\
\hline
\end{tabular}

Animals were administered QRT (20 mg/kg b.wt.) for five consecutive days. On the fifth day, mice were exposed to $3 \mathrm{~Gy}$ of gamma radiation. The blood was collected $24 \mathrm{~h}$ post irradiation time and assessed for comet assay. Values are mean \pm SEM for four mice per group. Abbreviations: IR: Radiation alone; QRT+IR: Quercetin+radiation; OTM: Olive tail movement; $\mathrm{QRT}+$ irradiation group compared with respective IR group: $\mathrm{b}=P<0.01$

known to be potent antioxidants which can scavenge the free radicals effectively. This part of the investigation has been carried out with an aim to evaluate the antigenotoxic potential of RUT and QRT and to understand the mechanisms underlying the same using irradiated mice.

The present study demonstrates the ability of RUT and QRT to reduce significantly the radiation-induced chromosome damage in mice bone marrow cells exposed to gamma radiation. Differences in radioprotection between dicentric and acentric chromosomes could be due to the different origins of chromosomes or chromatid aberration formation. It was evident that they were due to a significant decrease in the number of chromatid breaks, acentric fragments, rings, etc., The dicentrics and similar other aberrations were reduced to a minimal percentage on pretreatment with the drug before irradiation, in comparison to the radiation control group. Both scavenging and antioxidant properties of RUT and QRT are involved in the protection against the induction of chromosomal alterations by ionizing radiation.

Being a classic mutagen, ionizing radiation causes continuum of damage in DNA bases and sugars, cross-links, and more importantly induces single-strand breaks (SSB) or double-strand breaks (DSB), eventually leading to chromosomal aberrations. ${ }^{[21-23]}$ The major damage to DNA imposed by free radicals is strand breakage $;{ }^{[24]}$ the majority of free radicals may react with DNA by adding to the double bonds of the bases, forming base radicals. A small percentage of them react directly with the deoxyribose moiety by abstracting hydrogen atoms, leading to the formation of deoxyribose radicals. Both these events lead to strand breaks. ${ }^{[25]}$ Understanding the molecular basis of DNA damage by gamma radiation has been made possible using alkaline single-cell gel electrophoresis, i.e. alkaline comet assay ${ }^{[26]}$ and cytokinesis-block MN method. ${ }^{[27]}$

The cells usually possess a well-orchestrated enzymatic repair system which usually helps to repair the damaged part of the cell and also helps in the stabilization of the genome. It has been observed by Singh et al. ${ }^{[28]}$ that the majority of the primary lesions of DNA following irradiation are repaired immaculately within a range of a few minutes to a couple of hours. During the course of repair, some of the DNA breaks away from the enzymatic repair process. Lesions that remain incompletely repaired or unrepaired, especially DSB, are converted into cytogenetic alterations that may be visualized in proliferating cells. ${ }^{[29]}$ The genotoxicity of ionizing radiation is arbitrated through the generation of free radicals and by the action of ROS, which furthermore harm DNA and, consequently, can cause cell damage leading to cell death. ${ }^{[30]}$ The extent of DNA damage and repair could be detected efficiently by the alkaline comet assay, which has been successfully used in this study. The domain structures unwind, and when the preparations are subjected to electrophoresis, the broken DNA migrates away from the general mass of DNA in the nucleus. The amount of DNA that migrates is proportional to the number of strand breaks. Thus, this assay can detect single- and double-strand breaks at the level of DNA molecule, sites of incomplete repair, alkali-labile sites, and DNA-DNA and DNA-protein cross-links. The comet assay has successfully assessed the interactions of antioxidants with genotoxicants, ${ }^{[31]}$ and it has also proved a valid technique to evaluate whether antioxidants/micronutrients are able to protect the integrity of the genetic material. ${ }^{[2,32-34]}$ In the present study, the results from $\mathrm{MN}$ assays have shown that radiation is genotoxic and produces significant increase in MN induction, which was much higher when compared with the control cultures. These findings are in good agreement with the earlier studies. ${ }^{[35,36]}$

It has been observed with MN as well as comet assay that the menace of the radiation-induced genomic instability is reduced in the presence of RUT and QRT. Damage to DNA was attested by increased OTM with increasing doses of radiation. Decrease in the OTM of the comets treated with radiation in the presence of RUT $(10 \mathrm{mg} / \mathrm{kg}$ b.wt.) and QRT (20 mg/kg b.wt.) was observed, in comparison with the cells treated with radiation only. There are many studies 
which showed a reduction in radiation-induced damage in the presence of several other such antioxidants like ginseng ferulic acid and paeoniflorin that have been studied keeping micronuclei and comet assay as the endpoints. ${ }^{[37-39]}$

Further, with the aim to deduce precisely the biological relevance of the results obtained, comet assay was coupled with other measures of DNA damage, i.e. micronuclei, as proposed by Fenech and Morley. ${ }^{[40]}$ The difference between the effects measured in the comet assay and in the cytogenetic tests (micronuclei) is basically due to the variations in the type of DNA alterations that the test system detects, i.e., cytogenetic tests detect fixed mutations which persist for at least one mitotic cycle, while the comet assay merits the detection of a plethora of DNA lesions. Therefore, these assays have been used as established methods and have become the most reliable indicator of radiation-induced genetic damage.

Radiation-induced DSB, which lead to micronuclei formation, are considered to be one of the principal indicators of chromosomal damage because these are the chromatin fragments/whole chromosomes that are not incorporated into the main nucleus during mitosis. ${ }^{[41]}$ The MN assay, an important endpoint for the assessment of cytogenetic damage, was also used in previous studies with polyphenolic compounds to assess their antigenotoxic potential. ${ }^{[38,42,43]}$

The present study showed that RUT and QRT when administered orally did not cause significant formation of micronuclei, indicating their nontoxic effect at the doses we used. However, there was a significant reduction in the micronuclei frequency in the cells treated with RUT $(10 \mathrm{mg} / \mathrm{kg}$ b.wt.) and QRT (20 mg/kg b.wt.) before irradiation, when compared with the irradiated groups. These observations clearly indicate the protective effect of RUT and QRT against gamma radiation-induced DNA damage in treated mice. Earlier studies from our laboratory ${ }^{[44,45]}$ proved that oral administration of RUT (10 mg/kg b.wt.) and QRT (20 mg/kg b.wt.) for five consecutive days prior to irradiation enhanced the survival of mice, with an optimum survival rate of $69.3 \%$ and $62.5 \%$, respectively, and further increment in the RUT and QRT dose did not result in an increased survival. Therefore, in the present study, $10 \mathrm{mg} / \mathrm{kg}$ b.wt. of RUT and $20 \mathrm{mg} / \mathrm{kg}$ b.wt. of QRT were considered as the optimum effective doses for the protection against cytogenetic damage. The radioprotective agents are reported to have protection up to a particular dose, and may even be toxic thereafter ${ }^{[46]}$ In this study, the radiation-induced frequency of micronuclei formation in the bone marrow polychromatic and normochromatic erythrocytes was used as an index of genotoxcity, while the changes in the PCE/NCE ratio was an indication of suppression of erythropoiesis.

Irradiation of mice with different doses of gamma radiation resulted in a radiation dose-dependent elevation in the frequency of MnPCE and MnNCE in irradiation alone groups at $24 \mathrm{~h}$ post irradiation. These findings are in good agreement with earlier reports, where micronuclei formation due to irradiation has been reported in the bone marrow polychromatic and normochromatic erythrocytes observed at $24 \mathrm{~h}$ post irradiation. ${ }^{[47,48]}$ Yield of micronuclei depends upon the frequency of the induction of chromosomal fragments, their probability of exclusion at mitosis, proliferation status of cell population, cell cycle delay, and longevity of cells containing micronuclei. Erythropoiesis is a continuous process, and there is a constant progression of cells from erythroblasts through the PCE stage to NCEs. In mouse bone marrow, expulsion of erythroblast nucleus occurs about $6 \mathrm{~h}$ after the final mitosis; the subsequent PCE stage lasts in the bone marrow for $24 \mathrm{~h}$, and then for around the same time period in the peripheral blood, where the PCEs mature into NCEs. The micronuclei are not extruded from the erythroblasts along with the main nuclei, and can easily be detected in the mammalian anucleated PCEs. ${ }^{[14,49]} \mathrm{A}$ considerable fraction of MnPCEs migrate to the peripheral blood soon after their formation in the bone marrow, before maturing into NCEs. Some of the PCEs do mature into NCEs in the bone marrow itself, and then migrate to the peripheral blood. The micronucleated erythrocytes are expected to die by apoptosis. ${ }^{[50]}$ Pre-treatment with RUT $(10 \mathrm{mg} / \mathrm{kg}$ b.wt.) and QRT (20 $\mathrm{mg} / \mathrm{kg}$ b.wt.) reduced the frequency of radiation-induced micronuclei in the PCEs as well as in NCEs. This inhibition of radiation-induced micronuclei formation by RUT and QRT is in agreement with other studies reporting that dietary ingredients like vitamin $\mathrm{C}$ and $\mathrm{E}$ protect against radiation-induced micronuclei formation. ${ }^{[51]}$

Results from the present study suggest that RUT and QRT, naturally occurring phenolic compounds, effectively protect cells against radiation-induced genotoxicity. The mechanism of radioprotection by RUT and QRT may be ascribed to their antioxidant, anti-lipid peroxidative, and free radical scavenging properties, ${ }^{[44,45]}$ and by the inhibition of oxidative stress. Therefore, further investigations on RUT and QRT may prove their potential application as radioprotective agents or in offering protection against any free radical-mediated pathological condition.

\section{Acknowledgments}

We acknowledge the financial support by Board of Research in Nuclear Sciences (BRNS), Mumbai through Centre for Application of Radioisotopes and Radiation Technology (CARRT), Mangalore University, Manglaore. The authors are grateful to Dr. Archana P. R. and Prof. Sathish Rao, Head, Radiobiology Division, Manipal Life Sciences Centre, Manipal and Dr. J. G. R. Soloman of the Department of Radiotherapy and Oncology, Kasturba Medical College, Manipal, India for providing the necessary laboratory and irradiation facilities and help in dosimetry. 


\section{REFERENCES}

1. Stone HB, Coleman CN, Anscher MS, McBride WH. Effects of radiation on normal tissue: Consequences and mechanisms. Lancet Oncol 2003;4:529-36.

2. Nair CKK, Parida DK, Nomura T. Radioprotectors in radiotherapy. J Radiat Res (Tokyo) 2001;42:21-37.

3. Uma Devi P. Radioprotective, anticarcinogenic and antioxidant properties of the Indian Holy Basil, Ocimum sanctum (Tulasi). Indian J Exp Biol 2001;39:185-90.

4. Devasagayam TP, Sainis KB. Immune system and antioxidants, especially those derived from Indian medicinal plants. Indian J Exp Biol 2002;40:639-55.

5. Uma Devi P, Ganasoundari A, Rao BS, Srinivasan KK. In vivo radioprotection by ocimum flavonoids: Survival of mice. Radiat Res 1999;151:74-8.

6. Rao BS, Shanbhoge R, Upadhya D, Jagetia GC, Adiga SK, Kumar $\mathrm{P}$, et al. Antioxidant, anticlastogenic and radioprotective effect of Coleus aromaticus on Chinese hamster fibroblast cells (V79) exposed to gamma radiation. Mutagenesis 2006;21:237-42.

7. Rao BS, Upadhya D, Adiga SK. Protection of ionizing radiation-induced cytogenetic damage by hydroalcoholic extract of Cynodon dactylon in Chinese hamster lung fibroblast cells and human peripheral blood lymphocytes. J Environ Pathol Toxicol Oncol 2008;27:101-12.

8. Rao BN, Rao BS. Antagonistic effects of Zingerone, a phenolic alkanone against radiation-induced cytotoxicity, genotoxicity, apoptosis and oxidative stress in Chinese hamster lung fibroblast cells growing in vitro. Mutagenesis 2010;25:577-87.

9. Tiwari AK. Imbalance in antioxidant defense and human diseases: Multiple approach of natural antioxidants therapy. Curr Sci 2001;81:1179-87.

10. Reily PA. Free radicals in biology: Oxidative stress and the effect of ionizing radiation. Int J Radiat Biol 1994;65:27-33.

11. Shimoi K, Masuda S, Furugori M, Esaki S, Kinae N. Radioprotective effect on antioxidative flavonoids in gamma-ray irradiated mice. Carcinogenesis 1994;15:2669-72.

12. Olthof MR, Hollman PC, Vree TB, Katan MB. Bioavailabilities of quercetin-3-glucoside and quercetin-4'-glucoside do not differ in humans. J Nutr 2000;130:1200-3.

13. Park JB, Levine M. Intracellular accumulation of ascorbic acid is inhibited by flavonoids via blocking of dehydroascorbic acid and ascorbic acid uptakes in HL-60, U937 and Jurkat cells. J Nutr 2000;130:1297-302.

14. Schmid W. The micronucleus test. Mutat Res 1975;31:9-15.

15. Essers J, van Steeg H, de Wit J, Swagemakers SM, Vermeij M, Hoeijmakers $\mathrm{JH}$, et al. Homologous and non-homologous recombination differentially affect DNA damage repair in mice. EMBO J 2000;19:1703-10.

16. Hall EJ. Acute effects of total-body irradiation, Radiobiology for the Radiologist. $2^{\text {nd }}$ ed. Philadelphia, PA: Lippincott Williams and Wilkins; 2000. p. 42-59.

17. Seo YR, Kelley MR, Smith ML. Selenomethionine regulation of p53 by a ref1-dependent redox mechanism. Proc Natl Acad Sci U S A 2002;99:14548-53.
18. Jung HJ, Kim EH, Mun JY, Park S, Smith ML, Han SS, et al. Base excision DNA repair defect in Gadd45a-deficient cells. Oncogene 2007;26:7517-25.

19. Weiss JF, Landauer MR. Protection against ionizing radiation by antioxidant nutrients and phytochemicals. Toxicology 2003;189:1-20.

20. Maisin JR, Declève A, Gerber GB, Mattelin G, Lambiet-Collier M Chemical protection against the long-term effects of a single whole-body exposure of mice to ionizing radiation II. Causes of death. Radiat Res 1978;74:415-35.

21. Natarajan AT, Darroudi F, Jha AN, Meijers M, Zdzienicka MZ. Ionizing radiation induced DNA lesions which lead to chromosomal aberrations. Mutat Res 1993;299:297-303.

22. Dizdaroglu M, Jaruga P, Birincioglu M, Rodriguez H. Free radical-induced damage to DNA: Mechanisms and measurement. Free Radic Biol Med 2002;32:1102-15.

23. Hall EJ, Giaccia AJ. Radiobiology for the Radiologist: $6^{\text {th }}$ ed. Philadelphia, PA: Lippincott Williams and Wilkins; 2006. p. 77-91.

24. Sonntag VC. The Chemical Basis of Radiation Biology. London: Taylor and Francis; 1987. p. 33-44.

25. Gandhi NM, Gopalaswamy UV, Nair CK. Radiation protection by disulfiram: Protection of membrane and DNA in vitro and in vivo against gamma-radiation. J Radiat Res 2003;44:255-9.

26. Piperakis SM, Visvardis EE, Tassiou AM. Comet assay for nuclear DNA damage. Methods Enzymol 1999;300:184-94.

27. Maluf SW. Monitoring DNA damage following radiation exposure using cytokinesis-block micronucleus method and alkaline single-cell gel electrophoresis. Clin Chim Acta 2004;347:15-24.

28. Singh NP, McCoy MT, Tice RR, Schneider EL. A simple technique for quantitation of low levels of DNA damage in individual cells. Exp Cell Res 1988;175:184-91.

29. Pfeiffer P, Goedecke W, Obe G. Mechanisms of DNA double-strand break repair and their potential to induce chromosomal aberrations. Mutagenesis 2000;15:289-302.

30. Bolus NE. Basic review of radiation biology and terminology. J Nucl Med Technol 2001;29:67-73.

31. Gajecka M, Kujawski LM, Gawecki J, Szyfter K. The protective effect of vitamins $\mathrm{C}$ and $\mathrm{E}$ against $\mathrm{B}$ (a) $\mathrm{P}$-induced genotoxicity in human lymphocytes. J Environ Pathol Toxicol Oncol 1999;18:159-67.

32. Anderson D, Phillips BJ, Yu TW, Edwards AJ, Ayesh R, Butterworth KR. The effects of vitamin C supplementation on biomarkers of oxygen radical generated damage in human volunteers with "low" or "high" cholesterol levels. Environ Mol Mutagen 1997;30:161-74.

33. Heaton PR, Reed CF, Mann SJ, Ransley R, Stevenson J, Charlton CJ, et al. Role of dietary antioxidants to protect against DNA damage in adult dogs. J Nutr 2002;132(Suppl 2):1720-4S.

34. Novotna B, Topinka J, Solansky I, Chvatalova I, Lnenickova Z, Sram RJ. Impact of air pollution and genotype variability on DNA damage in Prague policemen. Toxicol Lett 2007;172:37-47.

35. Midander J, Revesz L. The frequency of micronuclei as a measure of cell survival in irradiated cell populations. Int J Radiat Biol Relat Stud Phys Chem Med 1980;38:237-42.

36. Jamali M, Trott KR. Increased micronucleus frequency in the progeny of irradiated Chinese hamster cells. Int J Radiat Biol 1996;69:301-7. 
37. Lee TK, Johnke RM, Allison RR, O`Brien KF, Dobbs LJ Jr. Radioprotective potential of ginseng. Mutagenesis 2005;20:237-43.

38. Srinivasan M, Sudheer AR, Pillai KR, Kumar PR, Sudhakaran PR, Menon VP. Influence of ferulic acid on gamma-radiation induced DNA damage, lipid peroxidation and antioxidant status in primary culture of isolated rat hepatocytes. Toxicology 2006;228:249-58.

39. Li CR, Zhou Z, Zhu D, Sun YN, Dai JM, Wang SQ. Protective effect of paeoniflorin on irradiation-induced cell damage involved in modulation of reactive oxygen species and the mitogen-activated protein kinases. Int J Biochem Cell Biol 2007;39:426-38.

40. Fenech M, Morley AA. Measurement of micronuclei in lymphocytes. Mutat Res 1985;147:29-36.

41. Kirsch-Volders M, Sofuni T, Aardema M, Albertini S, Eastmond D, Fenech M, et al. Report from the In Vitro Micronucleus Assay Working Group. Environ Mol Mutagen 2000;35:167-72.

42. Halder B, Pramanick S, Mukhopadhyay S, Giri AK. Anticlastogenic effects of black tea polyphenols theaflavins and thearubigins in human lymphocytes in vitro. Toxicol In Vitro 2006;20:608-13.

43. Rao BS, Rao N, Archana PR, Gayathri P, Shetty P. Antioxidant and radiation antagonistic effect of Saraca indica. J Environ Pathol Toxicol Oncol 2009;29:69-79.

44. Patil SL, Mallaiah SH, Patil RK. Antioxidative and radioprotective
Cytoprotection and immunomodulation by rutin and quercetin

potential of rutin and quercetin in Swiss albino mice exposed to gamma radiation. J Med Phys 2013;38:87-92.

45. Patil SL, Somashekarappa HM, Rajashekhar KP. Evaluation of the radioprotective action of rutin in mice exposed to gamma-radiation. Int J Biol Pharm Res 2012;3:12-8.

46. Nagata H, Sugahara T, Tanaka T. Radiation protection by 2-mercaptopropionylglycine in mice. J Radiat Res 1972;13:163-6.

47. Bhilwade HN, Chaubey RC, Chauhan PS. Gamma ray induced bone marrow micronucleated erythrocytes in seven strains of mouse. Mutat Res 2004;560:19-26.

48. Sudheer Kumar M, Unnikrishnan MK, Uma Devi P. Effect of 5 -aminosalicylic acid on radiation-induced micronuclei in mouse bone marrow. Mutat Res 2003;527:7-14.

49. Mavournin KH, Blakey DH, Cimino MC, Salamone MF, Heddle JA. The in vivo micronucleus assay in mammalian bone marrow and peripheral blood. A report of the U.S. Environmental Protection Agency Gene-Tox Program. Mutat Res 1990;239:29-80.

50. Chaubey RC, Bhilwade HN, Joshi BN, Chauhan PS. Studies on the migration of micronucleated erythrocytes from bone marrow to the peripheral blood in irradiated Swiss mice. Int J Radiat Biol 1993;63:239-45.

51. Odagiri Y, Karube T, Katayama H, Takemoto K. Modification of the clastogenic activity of X-ray and 6-mercaptopurine in mice by prefeeding with vitamins C and E. J Nutr 1992;122:1553-8. 